\title{
Polymer composite developed from discarded carpet for light weight structural applications:Development and Mechanical analysis
}

\author{
Rajesh Kumar Verma ${ }^{1, *}$, Balram Jaiswal ${ }^{1}$, Rahul Vishwakarma ${ }^{1}$, Kuldeep Kumar,",, Kaushlendra kumar $^{1}$ \\ ${ }^{1}$ Materials \& Morphology Laboratory, Department of Mechanical Engineering, Madan Mohan Malaviya University Technology, \\ Gorakhpur, Uttar Pradesh 273010, India
}

\begin{abstract}
Carpets are the three-dimensional product used as a floor covering in homes, offices, commercial centers, decorative purposes, etc. The average life span of the carpet is four to seven years and after that, it becomes solid waste. The discarded carpets are causing a significant hazardous effect on the environment, climate, soil, and various health issues. To overcome the increasing carpet waste, the reutilization of carpet is essentially desired. This article focuses on the development of polymer composites developed from discarded nylon carpets for lightweight applications. A modified technique of Vacuumassisted resin transfer molding (VARTM) was used to fabricate epoxy composites. The tensile and flexural tests evaluated the mechanical performance of the proposed composite. The modified composite is manufactured in two different configurations, namely, face- back-to-back-face (FBBF) and back- face to face- back (BFFB) with the help of the VARTM setup. The result demonstrated that the fabricated BFFB composite has a higher strength. The high-resolution microscopy test of the developed samples shows the feasibility of the composites produced from discarded carpet for lightweight functions. An attempt has been made to resue the waste for the fabrication of cost-effective products.
\end{abstract}

\section{Introduction}

Nowadays, carpet waste is a huge concern for the environment and the economy due to high disposal costs and environmental hazards. Only a small fraction of waste carpets gets recycled every year compared to produced carpet waste worldwide [1,2]. It is widely used as a floor covering, in homes, shopping complexes, offices, etc. [3]. A survey has been remarked that approximately 40,000 tons of carpet are discarded as landfills in the United Kingdom (UK) itself. This solid waste becomes a global concern for the environment and economy. [4]. The recycling of any material consists of multiple processing stages and needs heavy expenses. Carpets are non-biodegradable in nature, and it becomes hazardous for soil efficiency, causing environmental problems. The burning of carpets causes air pollution due to plastic content and fibers, which release toxic fumes. [5]. Based on the above issues, the present work highlights the fabrication and characterization of polymer composites develop from carpet waste. In the field of waste carpet re-utilization, many research works have been conducted for waste management. Various types of carpet waste are available in the garbage piles, which are quite difficult to recycle [6]. Various pioneers have performed experiments using carpet waste directly or indirectly in many forms. Onal et al. [7] explored the

*Correspondingauthor:rkvme@mmmut.ac.in characterization of the polymeric composites from jute fibers of carpets. The mechanical and physical properties of carpet jute yarn composites were examined. It has been found that that treating the yarn with a $25 \% \mathrm{NaOH}$ solution improved the fiber-matrix interface. Mishra et al. [8] fabricated structural composites from the post-consumer carpet using the VARTM process. This effort was made to convert such waste into an application form. The findings revealed that such composites are used as structures part like noise barriers. For a range of frequencies, it was found that the noise absorbed by fiber composite was better than conventional for a range of frequencies. Ucar et al. [1] fabricated a cementitious composite reinforced by carpet fibers. This work enhances the toughness of composites. As the fiber content in composite increases, the density of carpet decreases. The mechanical characteristics such as flexural, impact, and toughness of developed composites was examined to determine the feasibility. The results conclude that lightweight composite showed ductile behavior when three-point bending tests were performed, while in flexural strength, it increased with an increase in density. Islam et al. [9]developed insulation materials made from recycled textiles for acoustic and thermal applications. They stated that recycled textile composites are environmentally beneficial and have played an essential role in energy savings and pollution 
reduction. Muzzy et al. [10] used economic techniques to recycle post carpet composites without separating backing fibers with face fibers. They investigated and found that post carpet composites were used with matrix, which was potentially inexpensive with several applications. They also revealed that Nylon post carpet composites were better than polypropylene (PP) post carpet composites in terms of their properties. A large variety of applications of Post carpet composites in many forms helped reduce the activities of landfills. Pan et al. [11] fabricated composites from the discarded nylon 6/nylon 6,6 carpets and studied the mechanical properties, acoustics testing, and water stability. They stated that compression-molded composites had a greater elastic modulus, impact resistance, flexural strength, and sound absorption by $124 \%, 32 \%, 59 \%$, and $40 \%$, respectively as compared to the Jute/PP composites. The researcher stated that Styrene-Butadiene Rubber (SBR) greatly improved the impact resistance $\&$ sound absorption by maintaining the sound and flexural properties of fabricated composites. There are lots of researchers have shown their interests towards utilization of carpet and another form of wastes which could be utilized in any form. Basically, they have tried to use wastes because of its ease in availability and tried to convert it into some useful form by various methods. Some have mixed fibres of the carpet with other things, some other have done fabrication and characterization of composites which somehow helps in the utilization of waste. From aforesaid studies, it has been noticed that very limited work exist on the fabrication of composites from waste Nylon carpet.

In this paper waste, Nylon carpet waste was used to manufacture polymer composites using the VARTM technique. The flexural and tensile test was performed to evaluate the application potential of the proposed composites for structural applications. The scanning electron microscopy (SEM) tests were performed on the manufactured composite with the orientation of fiber back fiber (FBBF) and back fiber back (BFFB). This work target to utilize the massive carpet waste generated from domestic and industries applications.

\section{Materials and Methods}

The fabrication of composite materials was done from the Nylon waste carpet by infusion thermosetting epoxy resin. The carpet waste used for fabrication consists of Nylon carpets as waste fibers. The Epoxy with hardener was obtained from $\mathrm{M} / \mathrm{s}$. Universal Enterprises (Polymer Division) 78/44 Latouche Road Kanpur-208001 India. The VARTM setup was utilized to develop the composite samples.

\subsection{Fabrication of composite materials}

The Epoxy modified carpet waste Nylon layer was used in the Vacuum-assisted resin transfer molding (VARTM) technique [12]. The waste material was used as a reinforcing material in the Epoxy, which improved the interfacial adhesive characteristics of the developed composites between fiber and matrix material. For the strengthening of composite materials, the hardener is added at a ratio of 10:1 in mixed Epoxy. The VARTM method has the advantage of allowing a uniform flow of resin with minimum porosity and bubble formation in the preparation of the sample. Different items, machines, and devices that have been shown in Fig. 1 are resin trap, compressor, vices/clamps, tubes, etc. After preparing the mold, the setup was left undisturbed for 24 hours to solidify in ambient conditions.

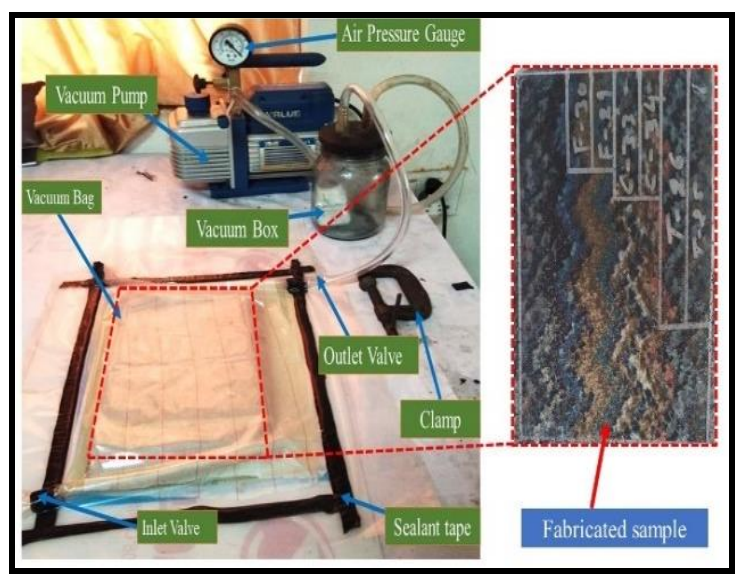

Fig. 1. Fabrication process using VARTM setup.

\section{Experimentation characterization}

This paper deals with the fabrication and characterization of Epoxy incorporated carper waste Nylon for structural composites. The orientation of the fabricated carpet composite was of FBBF and BFFB was taken. After fabrication, characterization of the fabricated composite was done by flexural and tensile test. As shown in Fig. 2, the Tensile and Flexural tests have been performed on Universal Testing Machine (INSTRON- 3382, Max. Load 100 KN). The Tensile test specimens were prepared under ASTM D3039 with size $(165 \times 20 \times 10) \mathrm{mm}$ [13]. The flexural testing has been performed according to ASTM D790 $(60 \times 20 \times 10) \mathrm{mm}$ [14]. The scanning electron microscopy (SEM) was performed to examine the structural integrity and failure mechanisms. Try to ensure that lines are no thinner than 


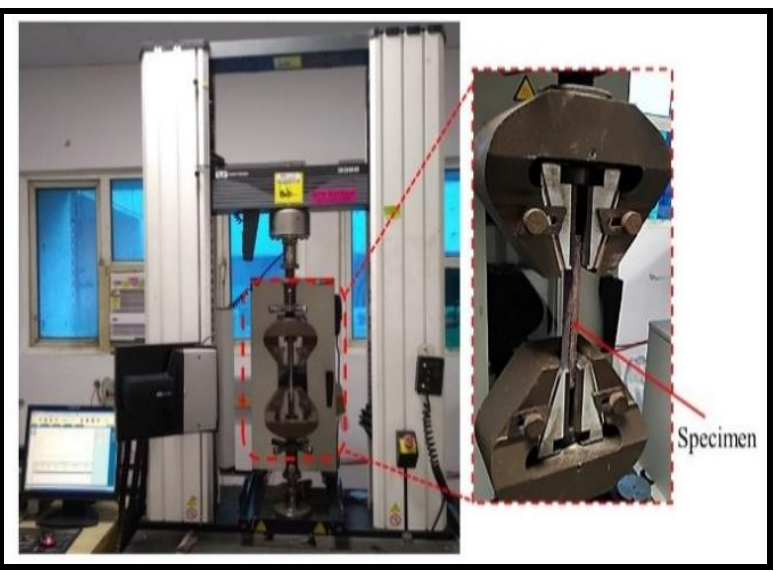

Fig. 2.UTM setup (INSTRON- 3382).

\subsection{Tensile Test}

The tensile test is one of the most common testing techniques to determine tensile strength and tensile modulus. The tensile tests were performed on two different test pieces of the same dimensions and material, and accordingly, two readings were found. According to the ASTM standard, the tensile test has been performed on fabricated composite. Fig. 3 shows the damaged test specimen nylon waste carpet composite. The load against the deformation curve is noticed in Fig. 4. On both samples, the loaddeformation result varies from linear to non-uniform after $2.1 \mathrm{~mm}$ deformations. The failure at peak load for both composites is absorbed due to their ductile nature. Moreover, Fig 4 also shows that BFFB samples can bear a higher load after the initial failure in a full load. Furthermore, variations in the peak load of FBBF and BFFB configuration have been observed due to the disparity in composite thickness. The failure of FBBF samples at a lower load indicates the presence of brittleness in the composite. The multivariate configuration and variations in the strength of face fibers lead to the deviation in the properties of carpets. Table 1 presents the tensile properties of the fabricated composites for both configurations. The average elongation of the BFFB specimen is higher than the FBBF specimen because the fibers positioned away from the neutral axis filled with resin have higher specific strength. The tensile strength of the fabricated composite of FBBF is $7.3 \mathrm{MPa}$, and BFFB is 11.37 . It can be observed that the high tensile strength of the BFFB is obtained as compared to the FBBF composite.

Table 1.Tensile properties of fabricated sample.

\begin{tabular}{|c|c|c|c|}
\hline $\begin{array}{c}\text { Sample } \\
\text { code }\end{array}$ & $\begin{array}{c}\text { Maximum } \\
\text { load (N) }\end{array}$ & $\begin{array}{c}\text { Tensile } \\
\text { strength } \\
\text { (MPa) }\end{array}$ & $\begin{array}{c}\text { Elongation } \\
\mathbf{( \% )}\end{array}$ \\
\hline FBBF & 919.5 & 7.3 & 1.59 \\
\hline BFFB & 2841.5 & 11.37 & 2.03 \\
\hline
\end{tabular}

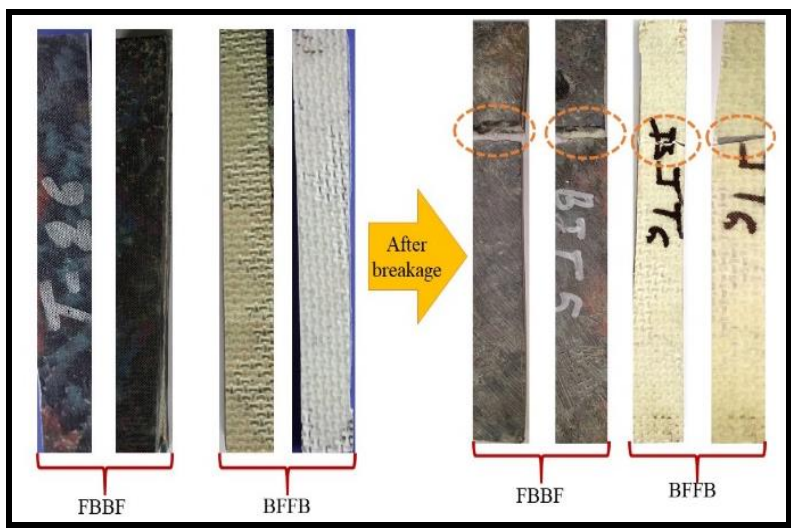

Fig. 3. Failure module of FBBF and BFFB sample.

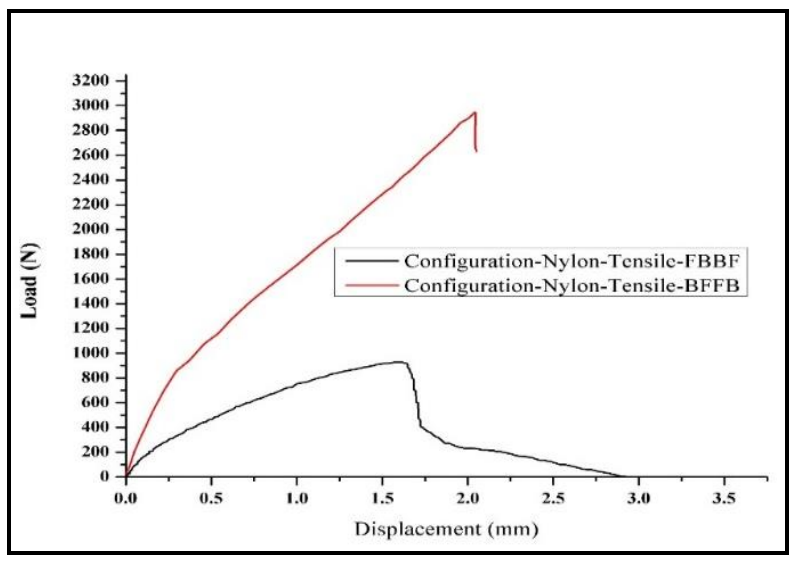

Fig. 4. Typical tensile load vs displacement curve.

\subsection{Flexural Test}

The most common purpose of a flexural bending test is to determine flexural strength and flexural modulus. The machine was directly linked to the computer in this test, so any deflection in the stress or strain during testing was sensed and shown through a graph in each sample. In this study, the flexural tests have been performed on two different test pieces of the same dimension and material, and accordingly. In order to perform the flexural test, the required dimension for testing of the composite was made to cut by ASTM D790 standard. The dimension was $60 \times 20 \times 10 \mathrm{~mm}^{3}$, and its cross-sectional area was $60 \times 20 \mathrm{~mm}^{2}$. Fig. 5 shows the samples after the flexural testing was performed. Table 2 presents the flexural properties of the fabricated composites for both configurations. 


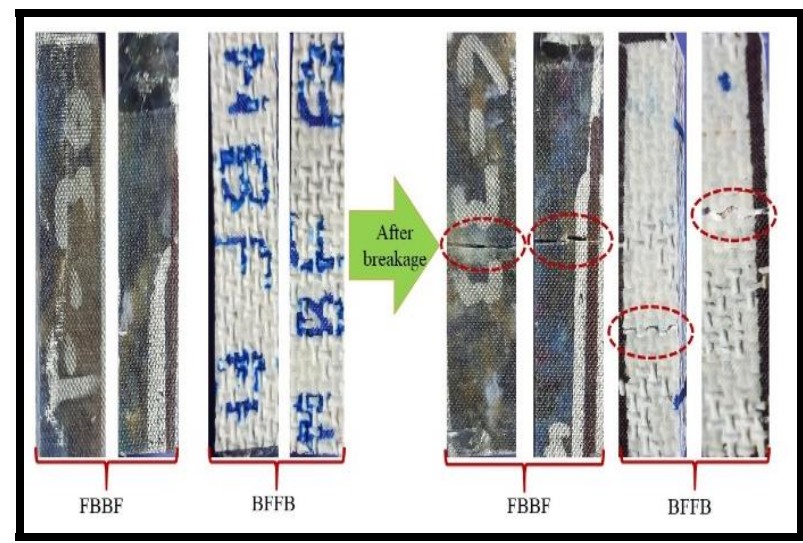

Fig. 5. Flexural module of FBBF and BFFB sample.

Table 2.Flexural properties of fabricated sample.

\begin{tabular}{|c|c|c|c|}
\hline $\begin{array}{c}\text { Sample } \\
\text { code }\end{array}$ & $\begin{array}{c}\text { Maximum } \\
\text { Flexural } \\
\text { load (N) }\end{array}$ & $\begin{array}{c}\text { Flexural } \\
\text { strength } \\
\text { (MPa) }\end{array}$ & $\begin{array}{c}\text { Maximum } \\
\text { Displacement }\end{array}$ \\
\hline FBBF & 2020 & 33.19 & 2.54 \\
\hline BFFB & 968 & 25.47 & 7.39 \\
\hline
\end{tabular}

The flexural strength of the prepared specimen was investigated at the constant thickness and span length. As shown in Fig. 6, the sharp peak in the BFFB configuration indicates that the fiber gets fractured promptly after splitting Epoxy. Fig. 6 demonstrated the load vs displacement curve and its shows that nonuniform zigzag peaks are generated by samples of FBBF, with a maximum load of $2020 \mathrm{~N}$ before fracturing. By comparison, a maximum load of $968 \mathrm{~N}$ will hold the BFFB configuration. The probable reason is due to the nylon carpet backrest tolerance to deformations of the peak load gap. The actual cause for the variations in flexural module between the FBBF and the BFFB configuration is the dispersion of Epoxy due to the difference in reaction between the Nylon backing and the fiber-infused resin.

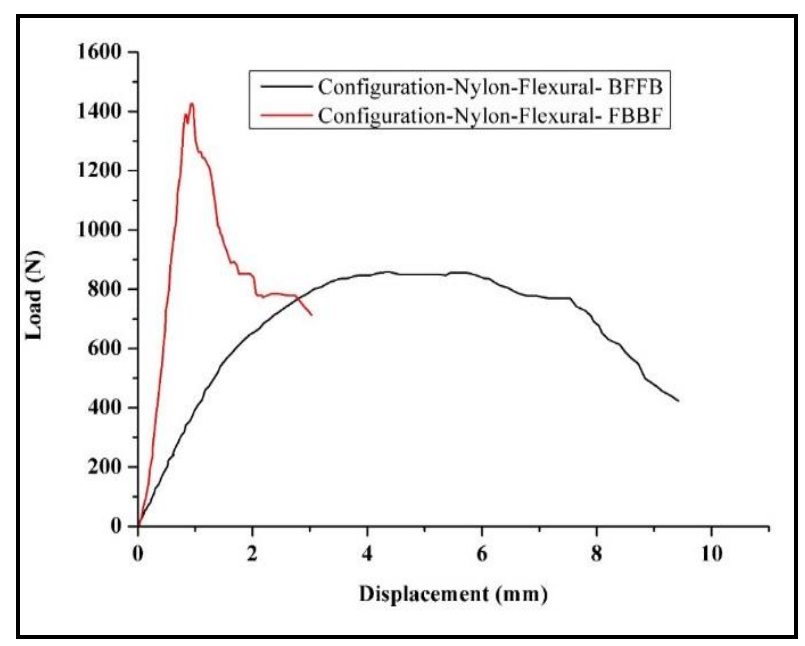

Fig. 6. Typical Flexural module load v/s displacement curve.

\subsection{Scanning Electron Microscope (SEM)}

Scanning Electron Microscope (SEM) is used to analyze the high-resolution image of the surface of the breakage sample up to micro and nano-level [15]. As shown in Fig. 7, the SEM analysis has been examined of fracture point after the tensile testing. The images produced by SEM show the extensive fiber breakage and good surface bonding. The images collected through SEM have different magnifications and resolutions up to different microns in different regions. It can easily visualize the fibers, surface textures, homogeneity between carpet fibers and Epoxy, and porosity of the sample from these images.

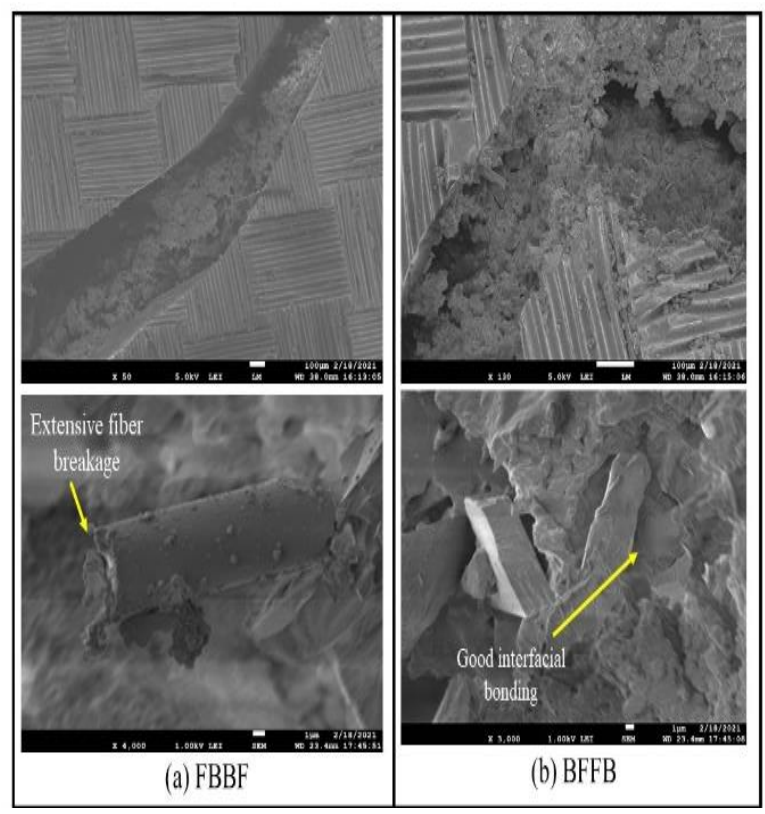

Fig. 7. SEM analysis of failure mode of fiber breakage in the composite after tensile test.

\section{Conclusion}

This paper focuses on the recycling of nylon carpet waste for the manufacturing of polymer composite. In two different configurations of FBBF and BFFB, the samples were prepared through the VARTM technique. The fabricated waste carpet composite samples of FBBF and BFFB configuration were characterized through flexural and tensile tests. Based on the findings, the following conclusion can be drawn:

-A tensile and flexural test noted that after rupturing of the epoxy matrix, the load was resisted by reinforcing material only. The results obtained by flexural and tensile tests in terms of forces required for the failure of the samples were used to find the strengths of the two carpet samples tested in each case.

-The fabricated BFFB composite has a higher strength than FBB. The result demonstrated that it could be economically used for structural application.

-From the images of SEM, it can be concluded that the higher porosity in the composite, the lower the strength and vice versa. The higher 
the homogeneity of mixture between carpet fiber and Epoxy in the composite, the higher will be the strength.

-By seeing the results obtained through different characterization, it can be concluded that the applications of such composites could be sound barriers, light containers, infrastructure composites, decorative purposes, selves to keep lightweight objects, etc.

The proposed work investigates the tensile and flexural properties of the composite manufacture from nylon carpet waste. Based on the result obtained, it has been noted that the proposed material can be used for lightweight applications such as sound barriers, heat insulation, wall tiles, etc. In future, the other investigations such as compression tests and advanced characterization are highly desired to understand the composite behavior in fatigue and creep conditions. The addition of some other carpet waste such as polypropylene, wool, polyester etc. and different hardener material can be used for composite development.

\section{Acknowledgment}

The authors would like to thank o/O DC (Handicrafts), Ministry of Textiles, Government of India, New Delhi, India.

\section{Declaration of conflicting interests}

The authors declared no potential conflicts of interest.

\section{Funding}

This research work is financially sponsored by o/O DC (Handicrafts), New Delhi, India, under R\&D Project ID: K-12012/4/19/2020-21/R\&D/ST.

\section{References}

[1] Ucar M, Wang Y. Int J Cloth Sci Technol; 23, 242 (2011).

[2] Ahmed HU, Faraj RH, Hilal N, Mohammed AA, Sherwani AFH.. Compos Part B Eng ;215, 108769 (2021).

[3] Mohammadhosseini H, Hasanah N, Shukor A, Rahman A, Sam M, Samadi M. Arab J Sci

Eng; 43, 1673 (2018).

[4] Cunningham PR, Green PG, Miller SA.. Resour Conserv Recycl, 169, 105496 (2021).

[5] Alabduljabbar H, Mohammadhosseini H, Tahir MM, Alyousef R. Mater Today Proc ; 39, 929 (2019).

[6] Serrano A, Meijer S, van Rijn RR, Coban SB, Reissland B, Hermens E, et al.. J Cult Herit; 47, 79 (2021).

[7] Onal L, Karaduman Y. Mechanical. J Compos Mater; 43, 1751 (2009).

[8] Mishra K, Vaidyanathan RK. Recycling; 4, 1 (2019).
[9] Islam S, Bhat G. J Environ Manage; 251, 109536 (2019).

[10] Muzzy J. Recycl Text A Vol Woodhead Publ Ser Text , 20, 203 (2006).

[11] Pan G, Zhao Y, Xu H, Hou X, Yang Y. J Clean Prod; 117, 212 (2016).

[12] Patel H V., Dave HK. Int J Mod Manuf Technol;12:125 (2020).

[13] D S Kumar*, M J Shukla, K K Mahato, D K Rathore RKP and BCR. Elsevier Ltd; 220, 75 (2015).

[14] Goriparthi BK, Suman KNS, Mohan Rao N. Compos Part A Appl Sci Manuf; 43, 1800 (2012).

[15] Zhang P, Akobi M, Khattab A. Compos Part B Eng; 168, 129 (2019). 